\title{
AVALIAÇÃO DA QUALIDADE DE VIDA NO TRABALHO NO SETOR DE CONSTRUÇÃO CIVIL: UTILIZAÇÃO DO MODELO DE WALTON
}

\author{
KOVALESKI, Aurélio ${ }^{30}$ \\ PEDROSO, Bruno ${ }^{31}$ \\ PILATTI, Luiz Alberto ${ }^{32}$
}

Recebido em: 2008-08-14

Aprovado em: 2008-09-19

ISSUE DOI: $10.3738 / 1982.2278 .133$

RESUMO: O estudo apresentado tem como objetivo aferir a Qualidade de Vida no Trabalho (QVT) de colaboradores do setor de construção civil. O instrumento de coleta de dados utilizado foi o modelo de Qualidade de Vida no Trabalho proposto por Walton (1973). O questionário foi aplicado a um grupo de 42 colaboradores de três empresas vinculadas ao setor de construção civil. Os resultados demonstram que todos os critérios apresentam forte correlação com a QVT dos colaboradores do setor de construção civil, e que os quesitos "remuneração justa e adequada" (50,00\%) e "oportunidades de crescimento e segurança" (53,00\%) apresentaram os piores índices de satisfação, enquanto os critérios "relevância social" (69,35\%) e "uso e desenvolvimento das capacidades pessoais" $(68,48 \%)$ apresentaram os maiores índices de satisfação. Conclui-se que, embora o índice de satisfação com a QVT apresente um escore de 61,76\%, a satisfação dos colaboradores do setor objeto de estudo não é bastante limitada em função do nível salarial que influência significativamente todas as outras facetas da QVT.

Palavras-chave: Qualidade de vida no trabalho. Modelo de Walton. Construção civil.

SUMMARY: This paper objectifies the measurement of the Quality of Work Life (QWL) of workers of the civil construction area. The instrument used was the model of Quality of Work Life purposed by Walton (1973). The questionnaire was applied to a group of 42 workers of three different companies of civil construction area. The results demonstrate that all the criteria presents a strong correlation with the QWL of the workers of the civil construction area, and the criteria, "adequate and fair compensation" (50,00\%) and "future opportunity for continued growth and security" (53,00\%), had presented the worst level of satisfaction, while the criteria "social relevance of work life" $(69,35 \%)$ and "opportunity to use and develop human capacities" $(68,48 \%)$ had presented the best levels of satisfaction. It is concluded that, though the level of satisfaction of QWL demonstrates as score $61,76 \%$, the satisfaction of the workers of the sector of civil construction is very limited in function of the remuneration level who impact directly in all the others criteria of QWL.

Keywords: Quality of work life. Walton's QWL model. Civil construction.

\footnotetext{
${ }^{30}$ Graduando em Engenharia de Produção em Controle e Automação pela UTFPR, bolsista do PIBIC/CNPq.

${ }^{31}$ Mestrando em Engenharia de Produção pela UTFPR, bolsista da CAPES.

${ }^{32}$ Doutor em Educação Física, professor do Programa de Pós-Graduação em Engenharia de Produção da UTFPR.
} 


\section{INTRODUÇÃO}

O trabalho tem sido constantemente valorizado na sociedade contemporânea. Trabalhadores de diferentes classes sociais têm sido afetados pelas constantes mudanças ocorridas no curso da história. Mudanças essas que, apesar de serem instituídas basicamente no trabalho, têm conseqüências na vida societária.

Para Pilatti (2007), o trabalho vem sendo humanizado no decorrer dos tempos. A diminuição da jornada de trabalho e a melhoria das condições laborais demonstram uma direção de evolução. Porém, a valorização dos trabalhadores da sociedade do conhecimento não se mostra compatível com os avanços tecnológicos nas organizações. A produção, na ótica capitalista, tende sempre a aumentar, reduzindo custos e atendendo a padrões de qualidade cada vez mais elevados. Com isso, o mercado de trabalho impõe qualificações mais sofisticadas aos trabalhadores do conhecimento.

O trabalho, por ser um fator que define a classe social, a condição financeira e a posição em relação à sociedade do trabalhador, é prioridade na vida das pessoas. Para Orpen (1990), o trabalho tornou-se parte central da vida das pessoas na sociedade, pelo fato de ocupar grande parte do tempo destas. Outro fator que demonstra a grande importância do trabalho para as pessoas é a concorrência para se obter um nível de educação avançado e, conseqüentemente, um melhor posicionamento no mercado de trabalho. Possibilidades como especializações e cursos de idiomas cada vez mais são valorizados, tudo para aumentar as possibilidades do indivíduo obter um melhor emprego ou para lhe proporcionar maior estabilidade em seu emprego.

O presente trabalho objetivou aferir a Qualidade de Vida no Trabalho de colaboradores no setor de construção civil. Para tanto, foi utilizado o instrumento para avaliação da QVT de Walton (1973) e, também, uma revisão de literatura na tentativa de conceituar os termos Qualidade de Vida (QV) e Qualidade de Vida no Trabalho (QVT).

\section{QUALIDADE DE VIDA}

A qualidade de vida, nas últimas décadas, vem sendo estudada por pesquisadores de diversas partes do mundo (KIERNAN; KNUTSON, 1990). Embora existam vários conceitos 
para o termo "qualidade de vida", muitos autores ainda consideram esse um conceito de alta complexidade para se definir. Há também autores que explicitam a impossibilidade de definir a mesma (FLECK, 2008).

A definição para QV, proposta pelo Grupo WHOQOL, recomendada pela Organização Mundial da Saúde (OMS), será a utilizada neste trabalho. De acordo com o grupo WHOQOL (1998, p. 01), QV pode ser conceituada como “a percepção do indivíduo de sua posição na vida, no contexto de sua cultura e no sistema de valores em que vive e em relação a suas expectativas, seus padrões e suas preocupações". O grupo WHOQOL ainda considera o conceito de QV algo muito amplo, que aborda várias dimensões. Os fatores que são incorporados nesse conceito são: o nível de independência, o estado psicológico, a saúde física, as relações sociais, as relações com aspectos significativos do meio ambiente e as crenças pessoais. (WHOQOL GROUP, 1998.)

Embora não exista um consenso sobre o conceito de QV, o Grupo WHOQOL destaca que três aspectos são freqüentes nos diferentes conceitos de QV:

- Subjetividade: A perspectiva do indivíduo. Passa a contar como realidade objetiva a partir da percepção do indivíduo;

- Multidimensionalidade: A qualidade de vida é composta por varias dimensões. Define que não é correto que um instrumento que mensure a qualidade de vida tenha somente um escore, ele deve ter escores específicos para cada domínio, como por exemplo, saúde física, estado psicológico, etc;

- Dimensões positivas e negativas: Para uma boa qualidade de vida existe a necessidade de aparecerem elementos presentes e a necessidade da ausência de outros elementos.

Frente a estes aspectos conceituais, percebe-se a importância da presença de fatores indissociáveis para se obter uma boa QV, assim como a importância da ausência de fatores negativos, considerados prejudiciais a $\mathrm{QV}$.

O modelo de QV do grupo WHOQOL, o WHOQOL-100, é baseado em 24 facetas, divididas em seis domínios, como demonstra o quadro 1. 


\begin{tabular}{|c|c|}
\hline DOMÍNIOS & FACETAS \\
\hline \multirow{3}{*}{ Domínio I - Domínio físico } & 1. Dor e desconforto \\
\hline & 2. Energia e fadiga \\
\hline & 3. Sono e repouso \\
\hline \multirow{5}{*}{ Domínio II - Domínio psicológico } & 4. Sentimentos positivos \\
\hline & 5. Pensar, aprender, memória e concentração \\
\hline & 6. Auto-estima \\
\hline & 7. Imagem corporal e aparência \\
\hline & 8. Sentimentos negativos \\
\hline \multirow{4}{*}{$\begin{array}{l}\text { Domínio III - Nível de } \\
\text { Independência }\end{array}$} & 9. Mobilidade \\
\hline & 10. Atividades da vida cotidiana \\
\hline & 11. Dependência de medicação ou de tratamentos \\
\hline & 12. Capacidade de trabalho \\
\hline \multirow{3}{*}{ Domínio IV - Relações sociais } & 13. Relações pessoais \\
\hline & 14. Suporte (Apoio) social \\
\hline & 15. Atividade sexual \\
\hline \multirow{8}{*}{ Domínio V- Ambiente } & 16. Segurança física e proteção \\
\hline & 17. Ambiente no lar \\
\hline & 18. Recursos financeiros \\
\hline & $\begin{array}{l}\text { 19. Cuidados de saúde e sociais: disponibilidade e } \\
\text { qualidade }\end{array}$ \\
\hline & $\begin{array}{l}\text { 20. Oportunidades de adquirir novas informações e } \\
\text { habilidades }\end{array}$ \\
\hline & 21. Participação em, e oportunidades de recreação/lazer \\
\hline & 22. Ambiente físico: (poluição/ruído/trânsito/clima) \\
\hline & 23. Transporte \\
\hline $\begin{array}{l}\text { Domínio VI- Aspectos } \\
\text { espirituais/Religião/Crenças } \\
\text { pessoais }\end{array}$ & 24. Espiritualidade/religião/crenças pessoais \\
\hline
\end{tabular}

Quadro 1: Domínios e facetas dos WHOQOL-100

Fonte: FAMED, 1998.

O WHOQOL avalia QV de forma global, abrangendo todos os aspectos relacionados a esta. Os domínios evidenciam tal abrangência, de forma que todos os aspectos da QV possuem escores individuais e são seccionados em facetas correspondentes a cada um desses.

\section{A QUALIDADE DE VIDA NO TRABALHO}

O termo QVT foi inicialmente usado no final da década de 60, originado pela General Motors e a United Auto Workers, para descrever o nível de satisfação no trabalho dos trabalhadores. Nesses primeiros esforços, através de programas de QVT, a cooperação entre gerentes e trabalhadores resultou em locais de trabalho onde os empregados passaram a ter 
maior participação nas decisões tomadas pela empresa e também na resolução de problemas dela (KIERNAN; KNUTSON, 1990). Os programas de QVT eram desenvolvidos inicialmente para melhorar o nível de satisfação do trabalhador no seu trabalho, sempre visando o aumento da produtividade.

Em meados da década de 70, a QVT direcionou seu enfoque às mudanças específicas e métodos, visando não apenas aumentar a produtividade dos empregados, mas também, despertar certa identificação com o trabalho e um sentimento de orgulho e participação no mesmo. Nos programas de QVT da década de 80, a preocupação passou a ser a "democracia industrial", que expressa maior poder de decisão aos trabalhadores dentro da empresa (KIERNAN; KNUTSON, 1990).

Percebe-se que nos conceitos iniciais de QVT, uma das principais finalidades era o aumento da produtividade, conseqüentemente, objetivando maiores lucros. Ao longo das décadas, outros focos foram incorporados, visando o bem estar do trabalhador perante diversos valores, como honra, auto-estima, importância do trabalho desempenhado, e maior participação do trabalhador diante a tomada de decisões dentro da empresa.

\section{CONCEITOS DE QUALIDADE DE VIDA NO TRABALHO}

Os conceitos de QVT vêm variando ao longo dos tempos, em função de diversas mudanças por qual o trabalho vem passando no decorrer das décadas. Mais imposições foram colocadas perante aos empregadores, que, por sua vez, as repassam aos trabalhadores.

De acordo com Pilatti (2005) alguns fatores de influência relacionados à qualidade de vida no trabalho são:

- Participação do empregado nas decisões que afetam o desempenho de suas funções;

- Reestruturação de tarefas, ou seja, criação de estruturas e sistemas para que estas ofereçam maior liberdade e satisfação no trabalho;

- Sistemas de compensações que valorizem o trabalho de modo justo e de acordo ao desempenho;

- Adequação do ambiente de trabalho às necessidades individuais do trabalhador;

- Satisfação com o trabalho.

Com base nesses fatores de influência, pode-se afirmar que a QVT apresenta diferentes aspectos que, sem exceção, apresentam relação direta com o bem estar do 
trabalhador, seja em relação à compensação que ele recebe por uma tarefa desempenhada (salário ou críticas e comentários dos respectivos superiores) ou através de um ambiente de trabalho adequado, com respeito mútuo entre os trabalhadores.

Para Limongi-França (1996), a qualidade de vida no trabalho é um conjunto de ações que uma empresa executa em busca de atender escolhas de bem-estar das pessoas que trabalham nela.

Essa ainda classifica a qualidade de vida no trabalho em três esferas:

- Biológica: fatores relacionados à saúde e necessidades fisiológicas, como sono, alimentação e atividade física.

- Psicológica: fatores relacionados à auto-estima e o desenvolvimento de capacidades, como autoconhecimento e relacionamento pessoal.

- Social: fatores relacionados com os benefícios sociais, melhoria das condições de vida e desenvolvimento profissional.

As esferas propostas por Limongi-França (1996) mostram que o trabalhador, para usufruir de uma QVT satisfatória, deve ter uma boa saúde, um bom convívio social (seja este com a família, amigos ou demais grupos sociais) e também um sentimento de bem estar relacionado ao trabalho, não somente com o trabalho propriamente dito, mas também, com o retorno que este lhe proporciona.

\section{MODELO DE QVT DE WALTON}

Pioneiro nos estudos de QVT, Walton (1973) relaciona diretamente a QVT com a humanização do trabalho e responsabilidade social da empresa. Esse defende a idéia de que deve haver um entendimento por parte da empresa em relação às necessidades e aspirações do indivíduo, por meio de uma reestruturação de cargos e de grupos de trabalho com maior autonomia.

Walton (1973) propõe oito categorias conceituais que mostram como avaliar a qualidade de vida no trabalho, e conseqüentemente um contexto para uma possível análise da mesma. São elas:

a) Remuneração justa e adequada

Em se tratando do quesito pagamento, pode-se inferir que há diversos fatores de influência. Dentre esses, podem ser elencados o nível de treinamento exigido, a responsabilidade imposta e os efeitos nocivos das condições de trabalho inadequadas. Fatores 
secundários, que também caracterizam a remuneração como justa, são a demanda e disponibilidade de profissionais com a habilidade para o trabalho que se pretende realizar, e também padrões de remuneração já estabelecidos em uma comunidade;

b) Condições de trabalho

É conveniente dizer que na sociedade, desde seus primórdios, existe um consenso sobre as condições de trabalho. Estas constituem um indicador negativo da QVT quando exprime situações onde o trabalhador se expõe a condições de trabalho prejudiciais à saúde, tais como a elevada jornada de trabalho. Reivindicações por melhores condições de trabalho são realizadas pelos sindicatos e pelo próprio Estado.

Ao longo das décadas, tais reivindicações resultaram na redução da jornada de trabalho, minimização dos riscos de acidentes de trabalho e a adequação da idade dos trabalhadores para empregos que possam oferecer qualquer nível de risco;

c) Uso e desenvolvimento das capacidades pessoais

O trabalho, com as mudanças impostas através da revolução industrial, tem se tornado algo cada vez mais fracionado, de forma a ficar sempre mais específico, e estreitamente controlado. Porém, tais tendências são variadas nos diferentes tipos de trabalho, perfazendo desta forma que o uso e desenvolvimento das habilidades de cada tarefa também seja variado.

São necessárias algumas qualidades no trabalho para que a realização de tais habilidades seja aperfeiçoada. Dentre essas qualidades, podem ser destacadas: autonomia, necessidade de uso de diversas habilidades, informações e perspectivas referentes ao trabalho executado, o planejamento do trabalho em sua totalidade;

d) Oportunidade de crescimento e segurança

O trabalho industrial é algo no qual se procurava, por meio de esforços e aquisição de novos conhecimentos, se obter uma boa aprovação perante os superiores, já que nesta época o trabalho era algo muito complexo. Nos dias atuais, o trabalho já não tem tanta complexidade, e as habilidades necessárias para o ele podem ser adquiridas em um curto espaço de tempo.

Promoções em termos de cargos e salários para os trabalhadores geralmente são concebidas em função de bom desempenho no trabalho, educação e bom relacionamento com seus superiores. Contudo, promoções dadas a cargos elevados são mais raras, pois requerem um alto nível de habilidades relacionadas ao trabalho. Habilidades essas que tendem a se tornarem obsoletas com o tempo. Profissionais com idade entre 30 e 35 anos ocasionalmente enfrentam problemas no trabalho. Tais problemas se devem ao fato desses trabalhadores defrontarem com uma "barreira" de conhecimentos e habilidades que precisam ser renovadas, ao mesmo tempo em que começam a reavaliar outros fatores de suas vidas fora do trabalho, 
como família e outras carreiras disponíveis. Isso tende a convergir para o desinteresse em aprimoramentos das habilidades, que poderiam ser obtidas a fim de se alcançar um melhor rendimento no trabalho;

e) Integração social no Trabalho

Os relacionamentos pessoais do trabalhador podem ser considerados uma habilidade que deve ser constantemente aprimorada, em função do trabalho e da carreira sempre possuírem vínculo com organizações sociais, que exigem essa habilidade para se obter progresso.

Para que o trabalhador passe a ter uma identidade satisfatória em relação ao trabalho e uma boa auto-estima, ele precisa presenciar a ausência de preconceitos e discriminações de qualquer espécie. Deve haver igualdade no trabalho, ou seja, a não formação de classes diferenciadas ou de uma cadeia hierárquica, a possibilidade de alcançar cargos superiores, o senso de trabalho em equipe e uma comunicação aberta entre os funcionários, no que diz respeito às idéias e sentimentos;

f) Constitucionalismo

O trabalhador tem sua QVT afetada por diversas decisões tomadas em seu favor ou sobre seu status dentro do ambiente de trabalho. A união entre os trabalhadores, como grupos e sindicatos, tem buscado trazer mais constitucionalidade para o ambiente de trabalho, com finalidade de proteger os funcionários, além de informa-los sobre os seus direitos, bem como garantir que esses sejam respeitados.

Alguns aspectos de constitucionalismo que propiciam um incremento na QVT são: privacidade, livre arbítrio, igualdade e imparcialidade.

g) Trabalho e vida

As experiências provindas do trabalho apresentam retorno na vida dos trabalhadores, podendo serem positivos negativos. Um aumento da carga horária, por exemplo, diminui o tempo do funcionários com suas outras atividades pessoais (família e tempo de lazer), podendo assim prejudicar a vida dele, ocasionando problemas em sua relação familiar;

h) Relevância social

As contribuições sociais de uma empresa têm relação direta com o emptegador, considerando que ao perceber ações boas em relação ao exterior da empresa, como responsabilidade com produtos e a responsabilidade ambiental, a auto-estima do trabalhador aumenta. Porém, o trabalho pode ser depreciado ao perceber atos sociais irresponsáveis da empresa, como corrupção e omissão perante assuntos importantes, o que pode levar a uma 
baixa auto-estima do funionário, que passa a dar pouco valor ao seu trabalho.

Na perspectiva de Walton (1973), é perceptível que a QVT se torna evidente quando o trabalhador tem seus direitos exercidos, quando se sente satisfeito com relação ao seu trabalho, tem oportunidades para utilizar seus conhecimentos e possibilidade de aperfeiçoar os mesmos, sente orgulho do trabalho que realiza, tem uma remuneração justa e que se faz suficiente perante suas necessidades e quando não corre riscos ou se sente inseguro.

\section{METODOLOGIA}

O instrumento utilizado para a coleta de dados foi o modelo para Qualidade de Vida no Trabalho proposto por Walton (1973), o qual é estruturado em 35 questões abertas com uma escala de respostas do tipo Likert, de cinco alternativas. As questões do instrumento estão divididas em oito critérios: Remuneração adequada, condições de trabalho, uso e desenvolvimento de capacidades pessoais, oportunidade de crescimento e segurança, integração social no trabalho, constitucionalismo, trabalho e vida, e relevância social. Os critérios são seccionados em sub-critérios, onde cada um desses representa uma questão.

O público alvo deste estudo foram trabalhadores vinculados ao setor de construção civil, de três empresas distintas, neste estudo denominadas Alfa, Beta e Gama. A aplicação do instrumento foi realizada pelo próprio pesquisador. Aos trabalhadores não-alfabetizados, a leitura das questões e respostas foi procedida pelo pesquisador.

$\mathrm{Na}$ empresa Alfa foram aproveitados 12, de 20 questionários aplicados. Na empresa Beta aproveitaram-se 5 questionários, de 7 aplicados, e na empresa Gama aproveitaram-se 87questionários de 15 aplicados. Totalizou-se 25 questionários aproveitados, de 42 questionários aplicados, apresentando assim um índice de aproveitamento de 59,52\% dos questionários. Os 17 questionários que não foram aproveitados foram descartados em função de preenchimento incorreto ou inadequado.

Os resultados obtidos a partir da aplicação do instrumento foram tratados em uma escala de 0 a 100. Foram tidos como referências os pontos 25 e 75, sendo que os valores abaixo ou acima desses são caracterizados como elevada insatisfação e elevada satisfação, respectivamente. Os valores compreendidos entre o intervalo 25-75, caracterizam os termos intermediários, onde o valor 50 representa a secção que divide o intervalo em insatisfação e satisfação. Dessa forma, os números abaixo de 50 são considerados insatisfatórios, enquanto os superiores a 50, são considerados satisfatórios. 


\section{RESULTADO E DISCUSSÃO}

Com relação aos oito aspectos constituintes da QVT de sua teoria, Walton (1973) define que a QVT é propiciada pela combinação de esferas relacionadas ao desempenho no trabalho e outras não relacionadas ao desempenho, mas que resultam em comportamentos e condutas que influenciam de forma direta no trabalho em si.

Os resultados da aplicação do modelo de QVT de Walton no setor de construção civil apresentaram a seguinte configuração:

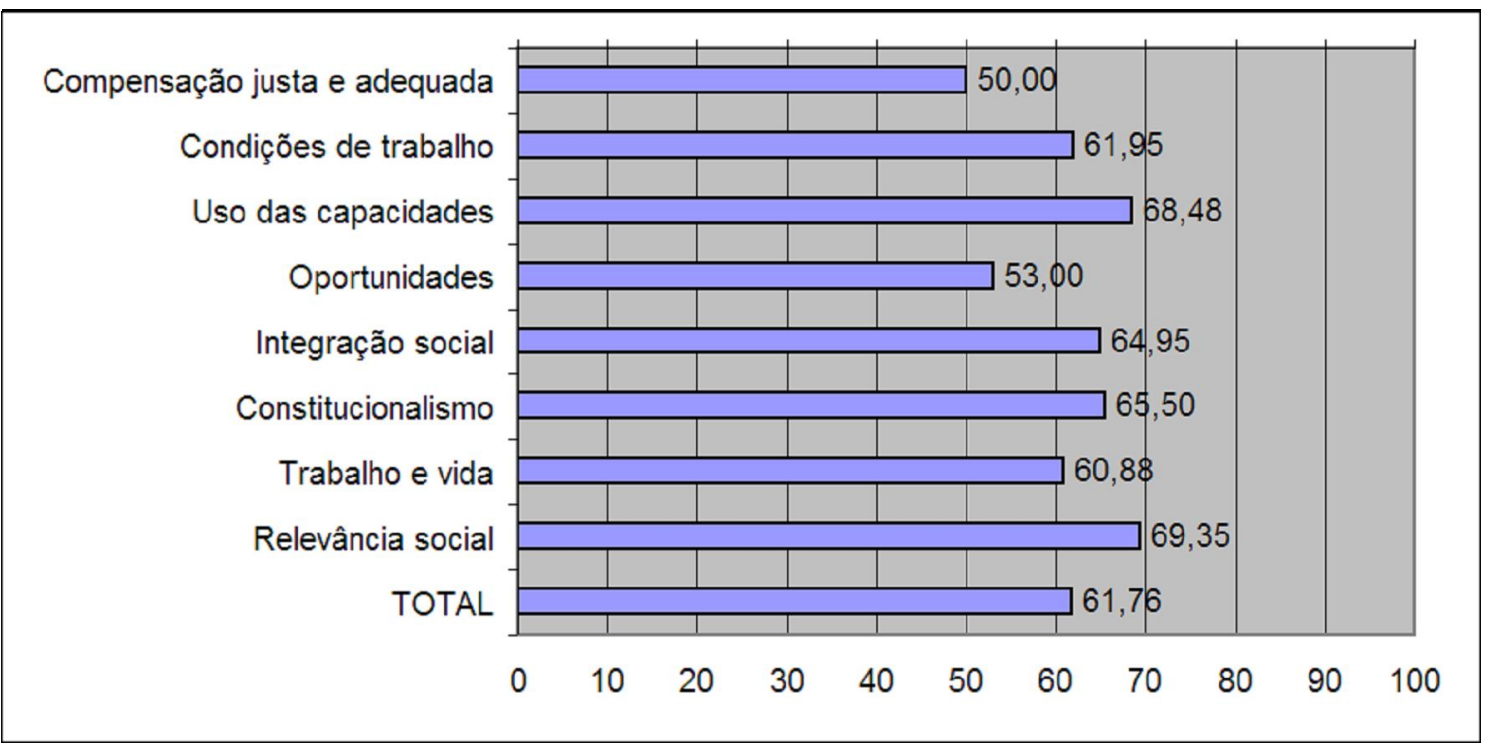

\section{Gráfico 1: Aspectos da QVT}

Fonte: Pesquisa de campo (2008)

Frente aos resultados, percebeu-se um nível indiferente de satisfação $(50,00 \%) \mathrm{em}$ relação à "remuneração justa e adequada" dos colaboradores. Isso é, os colaboradores em sua maioria, não apresentam qualquer manifestação de satisfação ou insatisfação com relação ao quesito remuneração.

No que diz respeito às "oportunidades de crescimento e segurança" (53,00\%), mesmo enquadrado como um nível satisfatório, percebe-se que o índice de satisfação é baixo, se comparado com os demais critérios.

Segundo Walton (1973), a remuneração do trabalhador, assim como as oportunidades 
de crescimento e a estabilidade no trabalho, podem depender das habilidades do profissional e também do mercado de trabalho no qual estão inseridos, como os fatores da disponibilidade de profissionais na área e da demanda por esses profissionais. Portanto, essa certa insatisfação dos trabalhadores com a remuneração e com a estabilidade e as oportunidades no trabalho pode ser causada por um alto numero de funcionários existentes na área e uma baixa demanda pelos mesmos.

Em contrapartida, os maiores índices de satisfação obtidos foram com relação aos aspectos "relevância social" $(69,35 \%)$ e o "uso e desenvolvimento das capacidades pessoais" $(68,48 \%)$. Os dados demonstram que, seguindo a linha de raciocínio de Walton (1973), percebe-se um sentimento de orgulho do trabalhador em relação ao trabalho executado, o que configura como um fator de aumento da auto-estima do mesmo. Com relação ao uso e desenvolvimento das capacidades pessoais, percebe-se a possibilidade de algumas qualidades presentes no trabalho possuírem influência direta na satisfação do colaborador. Dentre as qualidades, podem ser citadas: a autonomia, a necessidade do uso de diversas habilidades, informações e perspectivas referentes ao trabalho executado e o planejamento do trabalho em sua totalidade.

Quando um item apresenta influência significativa em outro item, diz-se que ambos estão correlacionados. A QVT, por se tratar de um conceito multidimensional, é mensurada a partir de vários critérios, que, eventualmente, podem se apresentar inter-relacionados. Quanto à correlação dos critérios entre si, e com a QVT dos colaboradores do setor objeto de estudo, foi obtida a seguinte matriz de correlação:

\begin{tabular}{|l|r|r|r|r|r|r|r|r|}
\hline & 1 & 2 & 3 & 4 & 5 & 6 & 7 & 8 \\
\hline Remuneração justa e adequada (1) & & & & & & & & \\
\hline Condições de trabalho (2) & 0,286 & & & & & & & \\
\hline $\begin{array}{l}\text { Uso e desenvolvimento das capacidades } \\
\text { pessoais (3) }\end{array}$ & 0,426 & 0,715 & & & & & & \\
\hline $\begin{array}{l}\text { Oportunidade de crescimento e segurança } \\
\text { (4) }\end{array}$ & 0,348 & 0,374 & 0,357 & & & & & \\
\hline Integração social no trabalho (5) & 0,459 & 0,64 & 0,567 & 0,414 & & & & \\
\hline Constitucionalismo (6) & 0,475 & 0,592 & 0,629 & 0,455 & 0,794 & & & \\
\hline Trabalho e vida (7) & 0,501 & 0,263 & 0,395 & 0,248 & 0,412 & 0,565 & & \\
\hline Relevância social (8) & 0,348 & 0,356 & 0,558 & 0,577 & 0,682 & 0,663 & 0,437 & \\
\hline TOTAL & 0,637 & 0,701 & 0,774 & 0,627 & 0,848 & 0,886 & 0,653 & 0,79 \\
\hline
\end{tabular}

Quadro 2: Matriz de correlação dos critérios de QVT

Fonte: Pesquisa de Campo (2008)

Com base na matriz de correlação, os critérios para avaliação da QVT apresentaram 
um significativo índice de correlação com a QVT. O critério "remuneração justa e adequada" mostrou não ter influência significativa sobre os outros critérios, contanto, tem impacto direto na QVT em sua totalidade. No entanto, apresentou baixa correlação com a QVT, se comparado aos outros critérios de avaliação. Com isso, é possível perceber que a remuneração pode não interferir na satisfação de outras esferas do trabalho em si, porém, para a obtenção de uma QVT de nível satisfatório, faz-se necessário uma remuneração justa e adequada.

Critérios que mostraram estar altamente correlacionados entre si são "constitucionalismo" e a "integração social no trabalho". O constitucionalismo tem como meta a obtenção por meio dos direitos trabalhistas um ambiente de trabalho mais justo e igualitário, o que certamente propicia uma maior integração social, em função da certa amenização no ambiente decorrente das melhores condições propostas pelo constitucionalismo.

O critério "condições de trabalho" apresenta grande influência no critério "uso e desenvolvimento das capacidades pessoais". As habilidades profissionais e pessoais do trabalhador, portanto, necessitam de boas condições de trabalho para serem corretamente usadas e aprimoradas.

O critério "integração social no trabalho" também apresenta influência direta na "relevância social do trabalho." Seguindo a teoria de Walton (1973), uma boa relevância social do trabalho, tem influência em se obter melhores relacionamentos pessoais internos.

A avaliação da QVT de forma global foi obtida a partir da média aritmética simples entre os escores de todos os critérios de avaliação. Nessa perspectiva, os colaboradores do setor de construção civil apresentaram um índice de satisfação de 61,76\%.

\section{CONSIDERAÇÕES FINAIS}

Com base nos estudos de Walton (1973), e dos resultados obtidos a partir da aplicação do instrumento de coleta de dados, pode se afirmar que a QVT satisfatória depende da combinação de diversos aspectos. Sendo assim, pode se afirmar também que, por envolver a aferição de diversos fatores, o conceito de QVT é amplo e complexo.

É perceptível que o setor de construção civil, em função da grande oferta de mão-deobra, na qual a demanda por profissionais da área pode não acompanhar a oferta de profissionais, leva assim a uma remuneração insatisfatória. Os resultados permitem concluir que, por se tratar de uma avaliação multidimensional, faz-se necessário que todos os critérios 
apresentem, minimamente, condições que proporcionem um índice de satisfação ao colaborador.

A correlação entre os critérios aponta que o elevado índice de satisfação em um determinado critério não significa que outro critério pode ser deixado em segundo plano. Percebe-se que, no setor de construção civil, todos os itens apresentam alta correlação com a QVT. Quanto à correlação dos critérios entre si, cabe ressaltar que, para que os colaboradores utilizem e desenvolvam suas capacidades pessoais, é necessário que o ambiente laboral apresente boas condições para tal.

Por fim, o índice de 61,76\% obtido a partir da média da QVT dos colaboradores do setor de construção civil permite concluir que a QVT desses é satisfatória. Contudo, aspectos como remuneração e também oportunidades e segurança apresentam um índice de satisfação restrito.

\section{REFERÊNCIAS}

ELIZUR, D; SHYE, S. Quality of Work Life and its relation to Quality of Life. Applied Psychology: An international review, Israel, v. 39, n. 3, p. 275-291, 1990.

FAMED - UNIVERSIDADE FEDERAL DO RIO GRANDE DO SUL/HCPA. Versão em português dos instrumentos de avaliação de qualidade de vida (WHOQOL) 1998. Disponível em <http://www.ufrgs.br/psiq/whoqol.html>. Acesso em 30 abr. 2008.

FLECK, M. P. A. Problemas conceituais em qualidade de vida. In: FLECK, M. P. A. et al. A avaliação da Qualidade de Vida: Guia para profissionais da saúde. Porto Alegre: ARTMED, 2008. cap. 1, p. 19-28.

KIERNAN, W. E; KNUTSON, K. Quality of Work Life. In: Quality of life: perspectives and Issues. Washington DC: American association on mental retardation, 1990. Cap. 11, p. 101114.

LIMONGI-FRANÇA, A. C. Indicadores empresariais de Qualidade de Vida no Trabalho: Esforço empresarial e satisfação dos empregados no ambiente de manufaturas com certificação ISO 9000. 1996. 251 p. Tese (Doutorado em Administração) - Faculdade de Economia, Administração e Contabilidade, Universidade de São Paulo, São Paulo.

ORPEN, C. The conceptualization of Quality of Working Life. Perspectives in Industrial Psychology, v. 7, n. 2, 1981.

PILATTI, L. A. Qualidade de vida no trabalho: perspectivas na sociedade do conhecimento. In: VILARTA, R. et al. Qualidade de vida e novas tecnologias. Campinas: Ipes editorial. 2007. 
PILATTI, L. A; BEJARANO, V. C. Qualidade de Vida no Trabalho: Leituras e Possibilidades no Entorno. In: GONÇALVES, A.; GUTIERREZ, G. L.; VILARTA, R. (Org.). Gestão da Qualidade de Vida na empresa. IPES Editorial. Campinas, SP. 2005.

WALTON, R. E. Quality of working life: what is it?. Sloan Management Review, Cambridge, v. 15, n. 1, p. 11-21, dec. 1973. 